\author{
Research Article
}

\title{
ANTIBACTERIAL EFFICACY OF MOUTH RINSING WITH 0.4\% SYZYGIUM CUMINI LEAF EXTRACT AGAINST STREPTOCOCCUS MUTANS: A RANDOMIZED CONTROLLED TRIAL
}

\section{Aniruddha Das ${ }^{1}$, Puja C Yavagal2*}

*1Public Health Dentist, Dentvalley Dental Clinic, Siliguri, Darjeeling, West Bengal.

2Professor, Department of Public Health Dentistry, Bapuji Dental College and Hospital, Davanagere, Karnataka.

\section{Article info}

Article History:

Received: 11-11-2021

Revised: 29-11-2021

Accepted: 04-12-2021

KEYWORDS:

Syzygium cumini,

Streptococcus mutans, mouthwash,

Antibacterial. \begin{abstract}
Syzygium cumini leaf extract possess a range of pharmacological properties such as antidiabetic, anti-inflammatory, antiulcerogenic, cardioprotective, antidiarrheal, antimicrobial, antioxidant and hepatoprotective activities. Objective of the study was to evaluate and compare the antibacterial efficacy of $0.4 \%$ Syzygium cumini leaf extract and $0.2 \%$ chlorhexidine containing mouthwashes on salivary Streptococcus mutans among children aged 7-8 years in a hospital setting. Methods: Twenty-four school children aged 7-8 years, fulfilling the eligibility criteria, were randomized into two groups. Group 1: received $0.4 \% \mathrm{~S}$. cumini leaf extract mouth wash and Group 2: received $0.2 \%$ chlorhexidine mouth wash. Saliva samples of the children were collected before and one hour after mouth rinsing with $10 \mathrm{ml}$ of interventional mouthwash, for S. mutans count analysis. Results: The results of the study showed that there was significant reduction in salivary S. mutans counts in both the groups post mouth rinsing with interventional solutions $(\mathrm{p}=0.002)$. However, intergroup comparison reveled that in Chlorhexidine group there was significantly more reduction in Salivary S mutans counts compared to Syzygium cumini mouth rinsing group. $(\mathrm{p}=0.03)$ Conclusion: There was reduction in salivary $S$ mutans counts after mouth rinsing with Syzygium cumini leaf extract. Hence, Syzygium cumini leaf extract mouthwash could be an effective aid for prevention and control of dental caries since it is safe, culturally acceptable and feasible.
\end{abstract}

\section{INTRODUCTION}

Mouthwashes which are used in dentistry for preventive and therapeutic purposes act by chemomechanical action. Chlorhexidine mouthwash is the gold standard in reducing $S$. mutans counts in saliva thereby preventing dental caries. But there are many adverse effects that are associated with chlorhexidine, which led to a shift in focus on potential natural alternatives with high antibacterial effects but less toxicity than chlorhexidine.[1] Herbal medicine is the major stay of about $75-80 \%$ of the world population, mainly in the developing countries, for primary health care because of better cultural acceptability, better compatibility and few side effects.

\begin{tabular}{|l|l|}
\hline \multicolumn{3}{|c|}{ Access this article online } \\
\hline Quick Response Code & \begin{tabular}{l} 
https://doi.org/10.47070/ijapr.v9i11.2154 \\
\hline
\end{tabular}
\end{tabular} \begin{tabular}{l}
$\begin{array}{l}\text { Published by Mahadev Publications (Regd.) } \\
\text { publication licensed under a Creative } \\
\text { Commons Attribution-NonCommercial- } \\
\text { ShareAlike 4.0 International (CC BY-NC-SA } \\
\text { 4.0) }\end{array}$ \\
\hline
\end{tabular}

India has well recorded and well-practiced knowledge of traditional herbal medicine. World Health Organization (WHO) encourages, recommends and promotes traditional/herbal remedies in national health care programs because the plant-based therapeutics are natural products, non-narcotic, easily bio-degradable, pose minimum environmental hazards, have less adverse effects which are easily available and affordable too.[2]

Eugenia jambolana (Syn. Syzygium cumini; Family: Myrtaceae) commonly known as 'Jamun' is a medicinal plant native to India. It grows naturally in tropical as well as subtropical zones. Rural people of India use the seed, fruit, leaf, bark of this plant as folk medicine to combat different types of diseases and disorders since antiquity. Scientific studies have shown that extracts of different parts of E. jambolana possessed a range of pharmacological properties such as antidiabetic, anti-inflammatory, antiulcerogenic, cardioprotective, antidiarrheal, antimicrobial, antioxidant and hepatoprotective activities. ${ }^{[3]}$ Leaves of 
S. cumini are known to be rich in flavonoids, tannins, gallic acid, ellagic acid and polyphenol derivatives known for anti-oxidant and antimicrobial properties. ${ }^{[4]}$ An in-vitro study done by Tahir et al in the year 2012 concluded that $0.4 \%$ of Jamun leaf extract had good antibacterial efficacy against S. mutans, ${ }^{5]}$ An in-vivo trial was planned with the aim of comparing the antibacterial efficacy of $0.4 \%$ Syzygium cumini leaf extract and $0.2 \%$ Chlorhexidine mouthwash on salivary Streptococcus mutans among school children aged 7-8 years in Davanagere city. Study tested the null hypothesis that there was no difference in the antibacterial efficacy of $0.4 \%$ Syzygium cumini leaf extract and $0.2 \%$ Chlorhexidine mouthwash on Salivary Streptococcus mutans counts among school children aged 7-8 years in Davanagere city.

\section{METHODOLOGY}

Study was a randomized controlled trial with concurrent parallel design. Study was conducted at the clinical premises of Department pf Public Health Dentistry, Bapuji Dental College and Hospital, Davanagere. Ethical clearance was obtained from the Institutional review board of the college where the study was conducted (Ref No.BDCH/Exam/509/201920). Parental consent of the study participants and assent from participating children were sought before the start of the study. The trial was registered in Central Trial Registry of India (CTRI/2021/03/ 031858 dated 10-3-2021). Sample size of 12 per group was determined as suggested by Julius for pilot studies. ${ }^{[8]}$ Therefore a total sample size of 24 children were selected based on the eligibility criteria. Children with at least one cavitated active carious lesion were included in the study. Children with significant untreated oral diseases like acute gingivitis, extensive tooth decay, acute oral infections, ulcerative gingivitis or stomatitis; unable to produce adequate amount of saliva for sampling; had low risk for dental caries (no history of restorations or presence of carious lesions); undergoing orthodontic treatment; hypersensitive to oral care products; were medically compromised and handicapped were not included in the study.

Preparation of Syzygium cumini leaf extract: The extract was prepared by air drying of Syzygium leaves followed by powdering it. Later powdered leaves were extracted with water by cold maceration method for two days and then it was filtered using Whatman No.1 filter paper12, followed by evaporating in rotary evaporator under vacuum at $40^{\circ} \mathrm{C}$. After evaporation of solvents, extracts were stored in refrigerator at $4^{\circ} \mathrm{C}$ until further use.

Preparation of $0.4 \%$ Syzygium cumini leaf mouthwash: Formulation of the mouthwash was done at Department of Pharmacognosy, Bapuji Pharmacy College, Davangere. A total of $30 \mathrm{gms}$ of $0.4 \%$ Syzygium cumini leaf extract was dissolved in 2 liters $(2000 \mathrm{ml})$ of distilled water and gently stirred with stirrer till completely dissolved. The prepared mouthwash was transferred to plastic bottles. Around 30gms of $0.4 \%$ concentration of Jamun leaf extract was dissolved in 2 liters $(2000 \mathrm{ml})$ of distilled water.

Chlorhexidine mouthwash: Commercially available $0.2 \%$ Chlorhexidine mouth rinse (Hexidine) by ICPA Health products ltd was used.

Randomization: Concealed randomization method was followed. Computer generated random sequence of code A and code B (total 24) was used to allocate the sites to the two interventional groups. The codes as per the sequence was placed in opaque concealed covers. Random allocation was done by a separate person not involved in the study. Interventional groups were Group 1: received $0.4 \% S$. cumini leaf extract mouth wash and Group 2: received $0.2 \%$ chlorhexidine mouth wash.

Procedure of Mouth rinsing: Each participant was given a bottle containing $10 \mathrm{ml}$ of interventional solution The bottle containers were identical in regard to shape and size to ensure that neither the subjects nor the dental examiner would know the identity of the mouth rinses. All the bottles were color coded

Procedure of Intervention: Baseline Salivary assessment of S. mutans, was done by collecting $1 \mathrm{ml}$ of unstimulated saliva of study participants in sterile containers. The respective mouthwash was distributed to all the participants. They were instructed to swish $10 \mathrm{ml}$ of mouthwash for one minute and spit it in the disposable cup provided to them. Participants were instructed not to eat or drink anything within 1 hour of using the interventional mouthwash. After 1 hour of using mouthwash (Post intervention) saliva collection was performed by the examiner.

Method of Saliva collection: $5 \mathrm{ml}$ of unstimulated saliva was collected at baseline and one hour after intervention from the participants by asking them to bend down the head and pool the saliva in the floor of the mouth. The pooled saliva was asked to spit into sterile containers. The samples were then sealed, labelled, coded and sent for microbiological analysis. The antimicrobial activity was assessed by disc diffusion method. Colony characteristics formed were studied and the number of colony forming units of S.mutans (CFU/ml of saliva) were determined using a colony counter.

Microbial analysis of Saliva samples for S. mutans count: Saliva sample was homogenized manually by stirring with a stirrer. $100 \mu \mathrm{l}$ of saliva was diluted with $1 \mathrm{ml}$ of saline (1:10 dilution). Using an inoculation loop ( $2 \mathrm{~mm}$ in diameter) $5 \mu \mathrm{l}$ of 1:10 dilution sample was streaked on Blood agar. This was incubated for 48 hours at $37^{\circ} \mathrm{C}$ in an atmosphere of $95 \%$ nitrogen and $5 \%$ carbon dioxide. After 48 hours of incubation period S. mutans appeared on the culture plate as small rough 
raised and adherent colonies and was confirmed by mannitol and sorbitol test. (Figure 1)

Blinding: The present study followed a triple blinding procedure. The investigator was blinded to mouthwash allocation. Subjects were blinded to mouthwash. Statistician and microbiologist were blinded to interventional groups.

Statistical Analysis: IBM SPSS Statistics for Windows, version 20 (IBM Corp., Armonk, N.Y., USA) was used for statistical analysis. Non parametric tests were used for data analysis as data did not follow normal distribution. Significance level was fixed at $p<0.05$.
Intra and Intergroup comparison of microbial counts was done using Wilcoxon signed rank test and MannWhitney U test respectively.

\section{RESULTS}

There was significant reduction in salivary $\mathrm{S}$. mutans counts in both the groups post mouth rinsing with interventional solutions $(p=0.002)$. (Table 1) However, intergroup comparison reveled that in Chlorhexidine group there was significantly more reduction in Salivary $\mathrm{S}$ mutans counts compared to Syzygium cumini mouth rinsing group. $(\mathrm{p}=0.03)$. (Table 1)

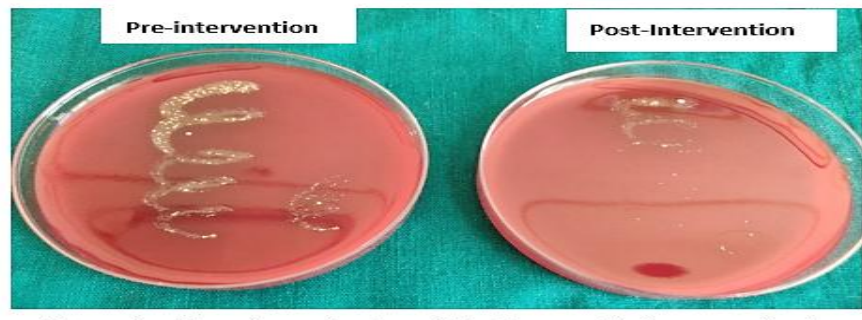

Figure 1a: $S$. mutans colonies on blood agar plate in a sample of Chlorhexidine mouthwash group

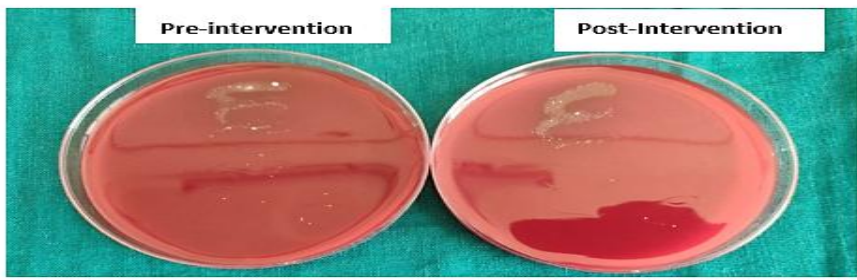

Figure 1b: S, mutans colonies on blood agar plate in a sample of $S$. cumini leaf extract mouthwash group

Table 1: Intra and inter group comparison of streptococcus mutans count $\left(\mathrm{x10}^{8} \mathrm{CFU} / \mathrm{ml}\right.$ of saliva) before and after intervention

\begin{tabular}{|l|l|c|l|}
\hline & $\begin{array}{l}\text { Pre-Test } \\
\text { Median (range) }\end{array}$ & $\begin{array}{l}\text { Post-Test } \\
\text { Median (range) }\end{array}$ & $\begin{array}{l}\text { Wilcoxon Signed } \\
\text { Rank Test (p value) }\end{array}$ \\
\hline Group 1 (N=12) & $52.5(97)^{\mathrm{A}}$ & $11.5(69)^{\mathrm{a}, \mathrm{A}}$ & $-3.059(0.002)$ \\
\hline Group 2 (N=12) & $67.5(94)^{\mathrm{B}}$ & $4(83)^{\mathrm{a}, \mathrm{B}}$ & $-3.061(0.002)$ \\
\hline Mann-Whitney U Test value (p value) & $58.5(0.435)$ & $35(0.033)$ & \\
\hline $\begin{array}{l}\text { Superscript lower-case letters indicate } \\
\text { significant differences between groups and } \\
\text { capital letters indicate significant differences } \\
\text { within groups. a-p=0.033, A-p=0.002, B- } \mathrm{p}=0.002\end{array}$ & & & \\
\hline
\end{tabular}

\section{DISCUSSION}

Modern concepts consider caries as an interaction between genetic and environmental factors in which social, behavioural, psychological, and biological factors are expressed in a highly complex interactive manner. The removal of plaque is utmost important to control dental caries that is commonly maintained by mechanical methods. However, in children, factors such as lack of dexterity and individual motivation and monitoring limit the effectiveness of tooth brushing. Children also experience difficulty in maintaining adequate plaque control, particularly at interproximal sites, which necessitates the use of chemotherapeutic agents for control of plaque. ${ }^{[9]}$ Colonization of tooth surfaces by bacteria is an important etiological factor in the most common oral diseases - dental caries, gingivitis, and destructive periodontal diseases. The literature is replete with studies establishing Streptococcus mutans as a major player in the formation of pit and fissure caries in the primary, mixed, and permanent dentition and that the amount of $S$. mutans in the saliva is related to the number of colonized surfaces. Therefore, decreasing the concentration of $S$. mutans in the oral cavity would have a great benefit with respect to decreasing the incidence of dental caries.[10] With the increase in antibiotics resistance, microorganisms and high cost of production of conventional synthetic compounds, there is a need for searching alternative antimicrobial products from natural sources. The rich chemical diversity in plants promises to be a potential 
source of antibiotic resistance modifying compounds and has yet to be explored. An in- vitro study concluded that the leaves of $S$. cumini possessed very good antibacterial activity against dental caries causing microorganisms and could be used as a potential source for making a phytomedicine that can be used to cure dental caries. ${ }^{[5,6]}$ The main tenet of studying the antimicrobial property of an herbal extract is that it is safe, abundantly available, culturally acceptable, economical and safer to the human body. [3] Based on the results of the study by Tahir et al, aqueous extracts of $\mathrm{S}$. cumini leaves showed highest antibacterial property against $S$. mutans. ${ }^{[5]}$ Hence it was decided to test the antimicrobial property of $S$. cumini leaf extract mouth rinsing against $S$. mutans and compare it with $0.2 \%$ chlorhexidine mouthwash. The results of the study showed that there was significant reduction in S. mutans count followed by mouth rinsing with $S$. cumini leaf extract. These results could not be compared to other studies as this was the first study to test the efficacy of $S$. Cumini leaf mouthwash in-vivo. However, few in-vitro studies have been done which shows the antibacterial efficacy of Jamun leaf extract against S. mutans. $[5,6]$ The antibacterial property of Jamun leaf extract are attributed to presence of high concentration of phenolics, flavonoids, alkaloids, saponins, terpenoids, gallic and ellagic acid polyphenol derivatives. [3,5,11] S. cumini leaf extract was prepared by cold maceration technique in the present study so that the decomposition of heat sensitive active constituents could be avoided. The major limitation of the study was its small sample size and post intervention antimicrobial analysis use was done at 1 hour of mouthwash use. Further conduct of in vivo studies with large sample size are recommended.

\section{CONCLUSION}

There was reduction in salivary $S$ mutans counts after mouth rinsing with Syzygium cumini leaf extract. Hence, Syzygium cumini leaf extract mouthwash could be an effective aid for prevention and control of dental caries since it is safe, culturally acceptable and feasible.

\section{REFERENCES}

1. S Shrimathi, Kemparaj U, Umesh S, Karuppaiah M, Pandian P, A K. Comparative Evaluation of Cocoa Bean

\section{Cite this article as:}

Aniruddha Das, Puja C Yavagal. Antibacterial Efficacy of Mouth Rinsing with 0.4\% Syzygium Cumini Leaf Extract Against Streptococcus Mutans: A Randomized Controlled Trial. International Journal of Ayurveda and Pharma Research. 2021;9(11):15-18.

https://doi.org/10.47070/ijapr.v9i11.2154

Source of support: Nil, Conflict of interest: None Declared
Husk, Ginger and Chlorhexidine Mouth Washes in the Reduction of Streptococcus Mutans and Lactobacillus Count in Saliva: A Randomized Controlled Trial. Cureus. 2019; 11(6): 1-8.

2. Sandhya S, Sudhakar K, David B, Rao KN Pharmacognostical standardization of Borassus flabellifer root. Annals of Biological Research. 2010; 1(4): 85-94.

3. Bag A, Bhattacharyya SK, Pal NK, Chattopadhyay RR. In vitro antibacterial potential of Eugenia jambolana seed extracts against multidrug-resistant human bacterial pathogens. Microbiological research. 2012 Jun 20; 167(6): 352-7.

4. Ayyanar M, Subash-Babu P. Syzygium cumini (L.) Skeels: A review of its phytochemical constituents and traditional uses. Asian Pacific journal of tropical biomedicine. 2012 Mar 1; 2(3): 240-6.

5. Tahir L, Ahmed S, Hussain N, Perveen I, Rahman S. Effect of leaves extract of indigenous species of Syzygium cumini on dental caries causing pathogens. Int. J. Pharma Bio Sci. 2012; 3: 1032-8.

6. Vieira TI, Gondim BL, Santiago BM, Valença AM. In vitro antibacterial and non-stick activity of extracts from leaves of Psidium guineense Sw. and Syzygium cumini (L.) Skeels on oral microorganisms. RGO. 2012 Nov 23; 60(3): 359-365.

7. Yadav SS, Meshram GA, Shinde D, Patil RC, Manohar SM, Upadhye MV. Antibacterial and Anticancer Activity of Bioactive Fraction of Syzygium cumini L. Seeds. Hayati Journal of Biosciences. 2011 Sep 1; 18(3): 11822.

8. Julious AS. Sample size of 12 per group rule of thumb for a pilot study. Pharmaceutical Statistics. 2005;4(4):287-91.

9. Lakade LS, Shah P, Shirol D. Comparison of antimicrobial efficacy of chlorhexidine and combination mouth rinse in reducing the mutans streptococcus count in plaque. J Indian Soc Pedod Prev Dent 2014; 32: 91-6.

10. Rupesh S, Winnier JJ, Nayak UA, Rao AP, Reddy NV. Comparative evaluation of the effects of an alum-containing mouthrinse and a saturated saline rinse on the salivary levels of Streptococcus mutans. J Indian Soc Pedod Prev Dent 2010; 28: 138-44.

11. Oliveira GF, Furtado NA, Silva Filho AA, Martins CH, Bastos JK, Cunha WR, et al. Anti-microbial activity of Syzygium cumini (Myrtaceae) leaves extract. Brazilian Journal of Microbiology. 2007; 38:381-4.
*Address for correspondence Dr. Puja C Yavagal

Professor,

Department of Public Health

Dentistry, Bapuji Dental College and

Hospital, Davanagere, Karnataka,

India.

Email: pujacyavagal@gmail.com 